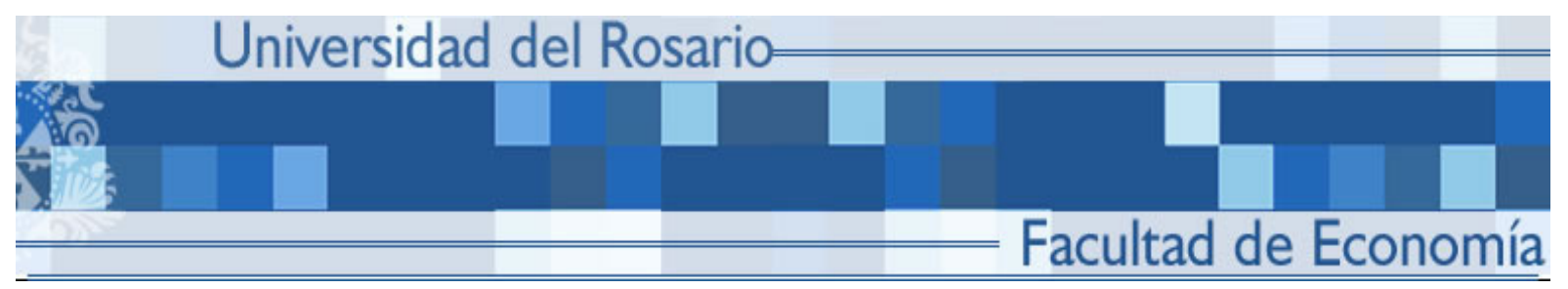

\title{
INEQUALITY OF OPPORTUNITY IN EDUCATIONAL ACHIEVEMENT IN LATIN AMERICA: EVIDENCE FROM PISA 2006-2009
}

Luis Fernando Gamboa

Fábio D. Waltenberg

No. 104

Julio 2011 


\title{
Inequality of Opportunity in Educational Achievement in Latin America: Evidence from PISA 2006-2009
}

\author{
Luis Fernando Gamboa* \\ Facultad de Economía \\ Universidad del Rosario \\ Bogotá, Colombia \\ Fábio D. Waltenberg ${ }^{\dagger}$ \\ Centro de Estudos sobre Desigualdade e Desenvolvimento (CEDE), \\ Departamento de Economia, \\ Universidade Federal Fluminense - UFF \\ Niterói, Rio de Janeiro, Brazil
}

July 25, 2011

\begin{abstract}
We assess inequality of opportunity in educational achievement in six Latin American countries, employing two waves of PISA data (2006 and 2009). By means of a non-parametric approach using a decomposable inequality index, $G E(0)$, we rank countries according to their degree of inequality of opportunity. We work with alternative characterizations of types: school type (public or private), gender, parental education, and combinations of those variables. We calculate 'incremental contributions' of each set of circumstances to inequality. We provide rankings of countries based on unconditional inequalities (using conventional indices) and on conditional inequalities (EOp indices), and the two sets of rankings do not always coincide. Inequality of opportunities range from less than $1 \%$ to up to $27 \%$, with substantial heterogeneity according to the year, the country, the subject and the specificication of circumstances. Robustness checks based on bootstrap and the use of an alternative index confirm most of the initial results.

Keywords: Inequality of Opportunity, economics of education, Latin America
\end{abstract}

JEL: D63, I24, O15

${ }^{*}$ Corresponding author. I acknowledge financial support from Colciencias and ICFES. Address: Calle 14 No. 6-25, Bogotá (Col). E-mail: luis.gamboa@urosario.edu.co. The authors would like to thank Dario Maldonado, José Trujillo, Marcia Carvalho, Kamila Correa and the participants of seminars at LACEA (Network on Inequality and Poverty), ECINEQ, ICFES and at the Centro de Estudos sobre Desigualdade e Desenvolvimento at the Universidade Federal Fluminense (CEDE/UFF).

†Address: Rua Tiradentes 17, Niterói-RJ-Brazil, CEP 24210-510. E-mail: waltenberg@economia.uff.br 


\section{Introduction}

The main objective of this study is to assess inequality of opportunity for educational achievement in Latin American countries following John Roemer's (1998) conceptual framework. Roemer defends the view that while a fraction of inequalities of a given outcome is unacceptable, another fraction is tolerable. This distinction is central in his concept of 'Equality of Opportunity' (EOp). The sources of inequality can be decomposed in those related to 'circumstances' and those related to 'effort'. The former is composed by all socially-inherited factors, such as one's gender or parental education; the latter includes factors under control of an individual, like the time or the intensity of effort devoted to a given activity, such as doing the homework she has been assigned. Individuals should be held responsible only for the level of effort they exert in comparison with those levels exerted by similar individuals, that is, those who belong to the same 'type' (i.e. who face similar circumstances); Roemer calls such conditional effort levels 'degrees of effort'. In turn, individuals should not be held responsible for unconditional - or 'intertype' - effort level differentials.

Although there are good reasons to care about inequality of opportunities taking income as the relevant achievement - such as in Roemer et al. (2003), Betts and Roemer (2005) or Checchi and Peragine (2010) - in our view it is also as important to investigate inequality of opportunities in terms of educational achievement - such as in Ferreira and Gignoux (2008) -, since education is a privileged sphere when it comes to 'level the playing field'. Educational outcomes are indeed important means for achieving a wide array of important personal goals. Being educated might also have an intrinsic value, regardless of the effect education might have on other, contemporaneous or future, goals. Finally, from a macroeconomic viewpoint, education quality, as measured by test scores, seems to be a key determinant of economic growth (Hanushek and Woessman, 2007).

In Latin America, the typical pattern of distributions of most socioeconomic indicators is one of large inequalities, and education is not an exception to the rule. Such unequal distributions of education are worrying for various reasons, which include possible restrictions to economic growth, underexploitation of potential positive externalities of education, and limits, for an important fraction of the population, to leading a materially comfortable life.

According to the EOp framework, in order to equalize opportunities for young people to acquire basic, compulsory, education, a given schooling system should ensure that a pupil's knowledge (as measured, for example, by her test scores) is not predetermined, to a great extent, by her 
circumstances, but rather that it is as much as possible the product of her conscious, individual, choices. In this study, we evaluate how far away different Latin American countries stand from this normative goal.

To make sure we could compare the degree of inequality of educational opportunity across Latin American countries, we have turned to waves 2006 and 2009 of OECD's PISA (Program for International Student Assessment) databases. We have chosen six Latin American countries which appear in both waves: Argentina, Brazil, Chile, Colombia, Mexico and Uruguay.

Different methodologies have been proposed in order to measure inequality of opportunities. ${ }^{1}$ We follow Checchi and Peragine's (2010) non-parametric approach, which allows us to rank distributions of educational achievements according to a specific index of inequality of opportunity. Since there is no undisputable definition of socially-inherited circumstances and since the methodology we employ, when combined with small samples, only allows for a parsimonious definition of them (cf. Ferreira and Gignoux, 2008)), we have decided to work with alternative characterizations of types: gender, school type (public or private), parental education, and combinations of those variables.

One innovation of this study deserves some comments. Although school type could be viewed as a choice, in some of our calculations we treat it as a socially-inherited circumstance. We do so for two reasons. First, because to the extent that being enrolled in a private or in a public school is a choice, we have no reasons to believe it is one made by 15-year-old pupils themselves, but rather by their parents. Second, in the Latin American context, enrolment in private schools is not a choice evenly offered to all parents; indeed it is usually restricted to well-off families. So following two complementary viewpoints, school type could be treated as a circumstance, rather than as a choice.

Another important feature of this study is that, in addition to working with simple partitions of the pupils' population along single dimensions (gender, or school type, or parental education), we also combine these dimensions pair-wise. Such procedure is important for at least three reasons. First, by doing so we are able to produce more complex definitions of types, possibly reflecting more reliably the actual circumstances people face. Second, since there is no undisputable definition of types, it is important to report results obtained using alternative definitions, acknowledging that different normative views can be associated with different characterizations of types (e.g., some observers might be willing to accept school type as a circumstance; others might not). Third, by

\footnotetext{
${ }^{1}$ Among which: Bourgignon et al. (2007), Dardanoni et al. (2005), Ferreira and Gignoux (2008), Lefranc et al (2009), Barros et al. (2009), Checchi and Peragine (2010)
} 
proceeding that way, we are able to calculate 'incremental contributions' of each set of circumstances when it is included as a conditioning factor. For example, we can calculate how much inequality of opportunity increases when we move from a definition of types based only on gender to another one based on both gender and parental education. Such strategy offers then useful insights about the role of each circumstance in determining the degree of inequality of opportunity in each country/subject/wave.

When it comes to applying Peragine and Checchi's (2010) approach, while there is a consensuns pointing to the necessity of employing an index belonging to the generalized entropy class, because of important axiomatic properties fulfilled by them, there is a debate concerning the choice of the index, namely whether $G E(0)$ or $G E(2)$ would be more suitable. We calculate inequality of opportunity employing $G E(0)$, and use $G E(2)$ as a robustness check.

Our results indicate that country rankings based on unconditional inequalities (using conventional indices) do not coincide with country rankings based on conditional inequalities (EOp indices), suggesting that inequality and inequity are not perfectly correlated. We are also able to diagnose recent trends (2006-2009) both in terms of educational inequality and of inequality of educational opportunity, which constitue fresh comparative evidence to Ferreira and Gignoux's (2008) study. Overall, gender alone does not seem to be an important source of unfair inequalities (except in reading), while parental education and school type appear to be quite important (mainly in Argentina and Brazil for the latter), with high levels of inequality of opportunity, even when are employed very parsimonious definitions of types, along single dimensions.

As expected, when a second set of circumstances is added up in the definition of types, the percentage of inequality of opportunities increases both in 2006 and in 2009, sometimes above $20 \%$. According to the year, the country, the subject and the specification of circumstances, inequality of opportunities range from less than $1 \%$ to up to $25 \%$, with considerable heterogeneity among the six countries, across subjects and across years. Robustness checks based on bootstrap and the use of an alternative index confirm most of the initial results.

The paper is organized as follows. Section 2 discusses methodological issues involved in measuring EOp with education data and the specific choices we have made, in particular the details of variables characterizing types. Section 3 is devoted to providing information about the data and to exposing descriptive statistics. In Section 4 the main results are reported, as well as some robustness checks, namely based on bootstrap and the use of an alternative index. Section 5 contains 
final remarks.

\section{Measuring inequality of opportunity in educational achieve- ment}

\subsection{Conceptual preliminaries}

John Roemer (1998) has defined the concept of equality of opportunity, which focuses, not on gross outcome inequalities, but on conditional ones. His intention is to distinguish the reasons underlying the achievement or underachievement of a certain outcome. Total inequality could be decomposed in morally unacceptable inequality (caused by circumstances beyond an individual's control like gender, race or socioeconomic origin etc.) and legitimate inequality (caused by different degrees of effort, autonomous choices etc.). While the former fraction of inequality should be prevented or require compensations, the latter kind should not be neutralized. The aim of an opportunity-equalizing set of policies would consist of shortening the breach in achievement (e.g., income) or access to advantages (e.g., access to college) for individuals who previously faced different opportunities - who belong to different types - but who have tried equally hard, that is, who have expended an equivalent degree of effort. ${ }^{2}$

Equality of opportunity is a concept that has been discussed and developed in the philosophical and economic literature over the last decades. However, having formalized it in precise terms, Roemer has helped organize the discussion. ${ }^{3}$ This long-lasting debate has turned to a great extent around where to draw the cut between what fraction of outcome gaps is to be compensated for and what is not. Dardanoni et al (2005), for example, argue that the exact content of circumstances and effort is a contentious issue that can vary from one sphere to another. For example, we might have one set of circumstances defining types when dealing with EOp in health (where, say, age might be a key circumstance) and another set when it comes to examine EOp in terms of labor market outcomes (where gender becomes a more central variable). Roemer himself refrains from making such contentious decision, preferring to work with a generic model, and claiming that the precise boundary between effort and circumstances is to be set by each society in each moment. As a

\footnotetext{
${ }^{2}$ As an example of 'equivalent degree of effort' for individuals belonging to different types one could think about two pupils whose effort levels are the median in their respective within-type distribution of effort.

${ }^{3}$ Recent related literature includes: Roemer (1996 and 2002), Van de Gaer (1993), Fleurbaey (1995 and 2008), Van de Gaer et al. (2001), Roemer et al. (2003), Ruiz-Castillo (2003), Peragine (2002, 2004a and 2004b), Checchi y Peragine (2010), Betts and Roemer (2004), Ooghe et al. (2007), Bourguignon et al. (2007 and 2007a), Lefranc et al. (2008 and 2009), Rodríguez (2008), Ferreira and Gignoux (2008) and Cogneau and Mesplé-Somps (2009)
} 
consequence, any choice of circumstances will be questionable. What is important then in our view in an empirical study is to: (i) spell out clearly the limits of any definition of types, (ii) explain the reasons why a certain definition of types makes sense in a given context, and (iii) compare the level of inequality of opportunity employing alternative definitions of types. We follow that procedure in this study, as will become clear below.

In education, the legitimacy of 'choice' might change considerably depending on the age of the individual. As Waltenberg and Vandenberghe (2007) argue it might be unreasonable to hold 15year-old pupils fully accountable for their effort - even when a detailed description of circumstances is available - given that they are not adults, but teenagers. The discussion around the boundary between circumstances and effort in the educational sphere is also undertaken by Peragine and Serlenga (2007). Acknowledging that a responsibility-related contribution to an achievement is less defendable in basic education than it is in higher education, those authors prefer to abstaint from using basic education data, turning then to higher education.

In the face of such objection on the legitimacy of choice when individuals are children and youths one would be tempted to expand the fraction of inequality attributed to circumstances. In a limiting case, each individual in itself would become a type, a situation in which gross inequality would be totally attributable to opportunity inequality and not at all to effort inequality. While that is clearly a limiting case, such normative view is indeed compatible with Roemer's approach. However, it is also true that important responsibilities where the role of an individual is crucial - such as driving or voting - are assigned to him or to her at the age of 16 in many countries. So while not fully accountable, teenagers are arguably at least partly accountable. Moreover, as we will explain below, the 'effort fraction' of inequality is more accurately interpreted as 'residual inequality' than literally as 'effort inequality'.

\subsection{Measuring issues}

Different methodologies have been proposed in order to measure inequality of opportunities. The one we adopt here has been developed in a series of papers by Vito Peragine and coauthors: Peragine (1999, 2002, 2004a, 2004b), Checchi, Peragine and Serlenga (2010), and Checchi and Peragine (2010). This procedure is an interesting translation of Roemer's concept: it is a non-parametric approach, which allows one to rank distributions of educational achievements according to a specific 
inequality-of-opportunity index. ${ }^{4}$ They do so by distinguishing the fraction of inequality which is attributed to circumstances (unacceptable) and the fraction which is attributed to effort (acceptable), and then assessing the relative importance of each of these two kinds of inequality. The 'effort fraction' of the estimation is more accurately interpreted not as being only due to effort, but rather as a combination of effort, luck (such as one's genes), and circumstances which, for some reason, could not be accounted for (e.g., due to unavailability of data, small sample sizes etc.) For this reason, we shall focus our analysis on the inequality-of-opportunity fraction, always acknowledging that we might be working with lower bounds of unfair inequality.

According to Peragine and co-authors' methodology, first, it is assumed that each individual $i$ is associated with a set of circumstances belonging to a finite set $\Omega=\left\{c_{1}, \ldots, c_{n}\right\}$. In the literature of EOp, a type $t$ is a set of people whose circumstances are $c_{\mathbf{t}}$. In the case of a population with $\mathrm{N}$ individuals, we denote $N_{t}^{x}$ the number of people of type $t$, who share similar circumstances, in the distribution of a specific outcome $x$ (income, schooling, etc.). For example, if we also have information about gender, the set of circumstances will be: $\{$ male, female $\}$. The availability of other circumstances will increase the details and the number of types. Second, according to their preferences and motivations, each individual exerts a certain degree of effort $e \in \Theta$. Following this notation, any individual could have an outcome function represented by an expression as $x(c, e)$; it is assumed that $x$ is monotonically increasing in the level of effort $e$. In our case, it implies that if a pupil of a given type obtained higher scores than an intratype fellow, then we will consider that she has exerted a higher level of effort. (We should not lose sight of the fact that effort has been defined as a residual, and should not be taken literally.) But a similar degree of effort exerted by individuals facing different circumstances should give rise to similar outcomes. Inequality of opportunities exists whenever two individuals from different types having exerted the same degree of effort achieve distinct outcomes. For example, if we assume gender is the only relevant circumstance, whenever the median performer woman and the median performer man achieve different scores, there is inequality of opportunity in terms of gender - at least in such specific percentile or 'tranche', namely, the median.

\footnotetext{
${ }^{4}$ The drawback is that, when comparing distributions, the rankings obtained may depend on the particular index used. Such problem does not happen in an approach based on dominance analyses (e.g., Pistolesi et al., 2005), which, on the other hand, is not always capable of providing complete rankings.
} 


\subsection{Empirical strategy}

Following Checchi and Peragine (2010), let the educational outcome distribution be represented by a vector $X=\left\{x_{1}, x_{2}, \ldots x_{N}\right\}$, where $x_{i}$ is pupil $i$ 's test score. As mentioned before, according to the circumstances included in our analysis, the distribution can be splitted into $t$ subsets according to individuals 'types', where $N_{t}^{x}$ is the number of pupils in each type. This step allows us to have a new representation of our vector $X$ as follows $X=\left\{\mathbf{x}_{1}, \mathbf{x}_{2}, \ldots \mathbf{x}_{t}\right\}$, where $\mathbf{x}_{1}$ is composed of pupils who belong to type $1, \mathbf{x}_{2}$ is composed of pupils who belong to type 2 , and so on. The advantage of this representation is that it includes subsets of pupils with the same circumstances. This partition bundles together individuals that may be distinct in many respects but who share the characteristics we believe are fundamental - and thus define types. Each vector $\mathbf{x}_{t}$ could then be partitioned into $k$ components as $\mathbf{x}_{t}=\left\{\mathrm{x}_{t 1}, \mathrm{x}_{t 2}, \ldots \mathrm{x}_{t k}\right\}$, where $k$ denotes individual effort. For example, $k$ could represent the median, or any other percentile of the distribution at which the pupil sits, also called 'tranche' in Checchi and Peragine (2010).

After that, we replace each pupil's score by the average score of pupils belonging to a given type and a given 'tranche' - e.g., the average score of pupils belonging to the type 'poor women' and who sit between the percentiles 10 and 15 - and we denote it $\left(\mu_{\mathbf{x}_{t k}}\right)$ and we obtain a new vector $X$ which includes as many different average scores as types times tranches we have. As an example, we might choose to partition the population according to gender ( 2 types) and to partition each within-type distribution according to tranches including $10 \%$ of the distribution (10 groups). In such case, we would have 20 average scores. We can now estimate an inequality index $I(X)$ reflecting the level of total inequality, and which will constitute the denominator employed in the calculation of the index of inequality of opportunity.

As for the numerator, we take the transformed distribution represented by vector $X$ and calculate the between-types inequality, $I\left(X_{B}\right)$, which expresses the level of inequality of opportunities. (Analogously, within-types inequality reflects inequality of effort). To obtain the fraction of inequality attributed to unfair aspects (circumstances) for each subject, we simply compute the ratio $I O(X)=I\left(X_{B}\right) / I(X)$. The portion of inequality that comes from effort is obtained residually, as the complement of $I O(X)$, that is $I E(X)=1-I O(X)$. This procedure requires the use of a decomposable inequality index, and good candidates are those belonging to the generalized entropy class.

The choice of the index, namely whether $G E(0)$ or $G E(2)$ is a contentious issue. On the 
one hand, while $G E(0)$ has the advantages of being path-independent (as defined by Foster and Shneyrow, 2000) and closer in spirit to Roemer's proposal of intolerance with respect to betweentypes inequality, it has the drawback of not being scale and translation invariant. On the other hand, $G E(2)$ would have the opposite advantages and drawbacks (cf. Ferreira and Gignoux, 2008). Following Checchi and Peragine (2010), in this study our main results are based on $G E(0)$, i.e., the mean logarithm deviation, which, for a distribution of the outcome $x$, can be represented by:

$I(X)=\frac{1}{N} \sum_{i=1}^{N} \ln \left(\frac{\mu_{x}}{x_{i}}\right)$. Additionally, we also calculate inequality of opportunity employing $G E(2)$, and report the results in the robustness checks' subsection.

\section{Data and descriptive statistics}

\subsection{PISA test scores and our choices of types}

We use data collected by the OECD in PISA 2006 and 2009. These are not only the most recent, but also are they to-date the most complete student achievement dataset in terms of the number of participating countries and of students covered by the samples. They include test scores of representative samples of students in dozens of countries, in three different subjects: mathematics, sciences and reading. The 2006 dataset is composed of about 355,000 students, while the 2009 dataset contains information on around 390,000 students. PISA also provides details about students' background and schools' functioning conditions, allowing researchers to observe various relationships between students'/schools' characteristics and pupils' performance.

An additional virtue of those datasets is their over-time comparability, since it is possible to contrast a fraction of results drawn from PISA 2009 with those of the three previous cycles of assessments. Finally, PISA data and scales play a privileged role - a kind of 'currency of school quality' - in the protocols that are being developed by Hanushek and Woessman (2007) for pooling and analyzing different test scores data and their relations with other socioeconomic variables. ${ }^{5}$

Two limitations of the dataset should be mentioned. First, individuals who repeated too many grades or who abandoned schools are not assessed by PISA. As a consequence we must interpret the indices we calculate as indicators of inequality of opportunity conditional on: (i) staying in

\footnotetext{
${ }^{5}$ An important limitation of PISA is the difficulty for inferring causality in econometric analyses, because of the following features: (i) the cross-sectional design of the datasets, (ii) test scores obtained at the age 15 reflect the cumulative effect of a series of factors over a long period of time, and not only the recent impact of schools; (iii) there is no information at the classroom level, but only at the individual level (mainly) and the school level (marginally). (Willms, 2006)
} 
the educational system, and (ii) not having repeated too many grades. Thus it should not be interpreted as an indicator of the degree of equality of opportunity for the cohort of 15-year-old individuals. Second, since the proportion of the cohort of 15-year-old individuals which has been excluded is not uniform across countries, the extent to which the calculated levels of inequality are close to the actual level might vary from country to country. These limitations suggest caution in the interpretation of the results. ${ }^{6}$

Given that our purpose is to obtain an accurate measurement of equality of opportunities, the set of circumstances is composed of three subsets, namely: gender, parental education (highest level among parents) and the type of school in which pupils are enrolled (public or private). The use of parental education as a socially-inherited characteristic is routine in the literature. It is clear that gender is a circumstance beyond pupils' control. Gender is important because future gender differentials in labor markets outcomes could depend on current gaps in educational achievements, such as those well-documented in the literature - typically boys outperform girls in mathematics exams, and the opposite pattern is observed in reading exams.

Although in many settings school type could be viewed as a choice, we treat it as a sociallyinherited circumstance. We do so for two reasons. First, because to the extent that being enrolled in a private or in a public school is a choice, it is one made by their parents. Second, in the Latin American context, enrolment in private schools is usually restricted to well-off families. So from two complementary viewpoints, choice of school type should not be treated as being under control of the individuals whose outcomes are at stake here, but rather as a circumstance. In PISA 2006, for example, the fraction of pupils whose parents were highly-educated and who were enrolled in public schools, with the exception of Uruguay, was less than $1 / 3 .^{7}$

In addition to working with simple partitions of the pupils' population along single dimensions (gender, or school type, or parental education), we also combine these dimensions pair-wise. Our specification includes gender ( 2 types), school type (2 types) and parental education ( 5 types). As an example, if we include gender and school type, we have 4 types, as follows $\Omega=\{$ (male private $),($ male - public $),($ female - private $),($ female - public $)\}$. Such procedure allows us to produce more complex definitions of types and to calculate 'incremental contributions' of each set

\footnotetext{
${ }^{6}$ The proportion of each countries' cohort which was represented by PISA samples was: (i) in 2006: Argentina (79\%), Brazil (55\%), Chile (78\%), Colombia (60\%), Mexico (54\%) and Uruguay (69\%); (ii) in 2009: Argentina (69\%), Brazil (63\%), Chile (85\%), Colombia (59\%), Mexico (61\%) and Uruguay (63\%).

${ }^{7}$ Argentina (26\%), Brazil $(27,6 \%)$, Chile $(8,7 \%)$, Colombia (31\%), Mexico(32, 2\%), Uruguay $(39,3 \%)$.
} 
of circumstances. For example, we can calculate how much inequality of opportunity increases when we move from a definition of types based only on gender to another one based on both gender and parental education. Such strategy offers evidence on the role of each circumstance in determining the degree of inequality of opportunity in each country/subject/wave.

The view of those who believe that assigning responsibility to 15 -year-old pupils makes no sense could be translated into Roemer's framework as treating each pupil as a type. In the face of the methodology employed in this study for calculating the degree of inequality of opportunity, if we treated each individual as a type, the fraction of inequality attributed to unequal opportunities would trivially amount to $100 \%$, since there would be no within-group (effort) inequality. The opposite normative view would consist of assigning full responsibility to pupils, in which case inequality of opportunity would trivially account for $0 \%$ of gross inequality, since all of it would consist of within-group (effort) inequality. These are limiting cases, against which our results can be compared.

\subsection{Features of the countries and PISA descriptive statistics}

Six Latin American countries have taken part in both PISA 2006 and 2009: Argentina, Brazil, Chile, Colombia, Mexico and Uruguay. ${ }^{8}$ Although heterogenous in some respects, these developing countries share some characteristics. As shown in Table 1, their GDP per capita ranges from US $\$ 3,000$ in Colombia to US $\$ 9,300$ in Argentina; their economies have being relatively stable with respect to other countries during the last decade; poverty incidence is high as compared to what is observed in OECD countries, affecting more than 20 percent of the population in most countries. Income inequality is high, with substantial Gini coefficients. These features have encouraged efforts towards social spending in health and education since the last decade, but these efforts are not sufficient. Public spending in education represents less than 6\% of GDP and less than $17 \%$ of public spending (with the exception of Mexico where it is about 25\%). Even the most populated countries, Brazil and Mexico, who also have the largest economies, fail to provide opportunities for their citizens, given that these countries present the highest illiteracy rates.

The fact that Latin American countries did not perform well by international standards has been widely discussed. In terms of average score, among the 57 countries that participated in PISA 2006 all the Latin American countries were ranked in the bottom 1/4 of the distribution with

\footnotetext{
${ }^{8}$ The absence of Colombia in PISA 2000 and 2003 prevents us from using those waves. In PISA 2009, Peru and Panama have joined the group for the first time.
} 
Brazil and Colombia having the lowest average scores, and Uruguay the highest. There are clearly two groups of countries, with Mexico, Uruguay and Chile showing relatively higher average scores than the other three, Argentina, Brazil and Colombia. As an illustration, the difference between Colombian pupils' score and those of other countries is statistically significant only when compared to the three higher scoring countries.

Average scores for each of the six countries appear in Table 2, in which we have also included the average scores for some specific percentiles (i.e. 5th and 95th), as well as those by school type and by gender. The fact that the ordering of countries for percentiles differs from that of average scores is already an indicator that the countries distributions differ.

In 2006, Chile's and Uruguay's average scores in the three subjects stand above those of other Latin American countries. However none of Chile's and Uruguay's results reach the average scores of OECD countries. Argentine, Brazilian, and Colombian pupils' average scores are more than 100 points lower than the OECD average. In 2009, the relative superiority of Chile and Uruguay over the rest of the countries remains. The difference between the country showing the highest average score and the one presenting the lowest is 50,68 and 57, for mathematics, sciences and reading, respectively. For 2009, these figures shrink to 47, 51 and 46, respectively.

Confirming a usual pattern found in the literature, we observe that boys outperform girls in mathematics, girls do so in reading, and in sciences there is no clear gender advantage. Gender average patterns in 2009 are replicates of those of 2006 but in higher-performing countries such gender gaps are smaller.

One specificity of Latin American educational systems lies in their high levels of social segregation across school types: socially disadvantaged individuals pupils usually study in public schools; socially advantaged enrol in private schools. In all subjects the average performance is substantially lower in public than in private schools. In some countries, the difference is huge, reaching up to one standard deviation of the OECD distribution (100 points). In the reading exam, the difference in Brazil is about 111 points in 2006, while Chile exhibits smaller differences.

When we focus on the distributions' tails, observing the performance gap between those pupils sitting on the 95th percentile and those sitting on the 5th percentile, an interesting pattern emerge. On the one hand, in 2006 such ratio 95/5 is higher than 2 in all the countries (with the exception of Mexico in sciences), and systematically above the ratios for OECD countries. On the other hand, these differences decline from 2006 to 2009 for all countries in all subjects (except for Uruguay in 
sciences).

\section{Results}

We have decomposed gross inequality into its 'opportunity' and 'effort' fractions, according to different definition of types. We have two types when gender alone is taken up; two when school type is the criterion (public and private); and five levels of pupil's parental education (none/primary, lower secondary, upper secondary, vocational tertiary, non vocational tertiary). We have also combined these categories, constructing more complex patterns of types, each with two subsets of circumstances. For example, ten types defined for every combination of gender (2) and parental education (5) or school type (2) and parental education (5).

Tables 3 and 4 summarize the results for 2006 and 2009, respectively. It should be noticed that in both tables, in addition to results concerning each of the six countries separately, we also report results regarding a fictitious country called 'Latin American', which is composed of observations of the pooled sample for all six countries.

When only parental education is used in the definition of types, we can observe in Table 3 (column I) that the percentage of unfair inequality in 2006 ranges from $8.2 \%$ (Colombia) to $19.7 \%$ (Chile) in mathematics. Those same two countries stand as fairest and unfairest in sciences, with $6.9 \%$ versus $17.3 \%$, respectively. In the reading exam, while Chile maintains its record of unfairest country, Argentina takes the place of Colombia as fairest one, with $14.2 \%$ versus $5.5 \%$, respectively

Regarding gender, the magnitudes are much lower in math and sciences, ranging from $0.3 \%$ to $3.0 \%$, (Table 3, column II). Those low magnitudes indicate that (for both subjects) the distributions of scores for each gender are close to each other, particularly in sciences. In reading, however, the magnitudes become larger, ranging from a minimum of $1.2 \%$ in Chile to a maximum of $7.8 \%$ in Argentina. The latter result suggests that, not only girls outperform boys in reading on average, but that the distributions of scores for each gender are located far apart in many different tranches.

When it comes to school type (column III in Table 3), figures are larger than with gender, and comparable to those obtained with parental education. They range from a minimum of $2.9 \%$ (Colombia, reading) to a maximum of $19.0 \%$ (Brazil, mathematics). In this respect, Argentina and Brazil stand apart as the two unfairest nations, while Colombia and Mexico present the lowest record of inequality of opportunity.

Overall, gender alone does not seem to be an important source of unfair inequalities (except 
in reading), while parental education and school type appear to be quite important (mainly in Argentina and Brazil for the latter), especially if we remember that the large figures presented in columns I and III of Table 4 have been obtained according to very parsimonious definitions of types, along single dimensions.

As for 2009 results (Table 4), once again gender is more relevant in the reading exam (Column I). Just as in 2006, inequality of opportunity is larger when circumstances are defined in terms of parental education (ranging from $7.0 \%$ to $17.4 \%$ ) or school type $(3.5 \%-19.6 \%$ ) than when gender is employed (0.1\%-6.6\%). There are important oscillations across the years in the calculated levels of inequality of opportunity, particularly in Chile (downwards), Uruguay and Colombia (upwards)..$^{9}$

As expected, when we add a second set of circumstances to the definition of types, the percentage of inequality of opportunities increases both in 2006 and in 2009 (columns A, B and C in tables 3 and 4). While still far from the $100 \%$ fraction of total inequality attributable to inequality of opportunities had we defined each person as a type, some cells in those tables present figures that in our view are extremely large, sometimes above $20 \%$, with an overall highest of $24.7 \%$ of inequality of opportunity obtained using the distribution of mathematics scores of Brazilian pupils in 2006 (23.3\% in sciences for Argentina 2009).

In Table 5, incremental contributions after the addition of another dimension into the definition of types are reported. Argentina and Brazil exhibit greater increases in the fraction of inequality of opportunities when an additional circumstance is added. For example, when school type is added to parental education in 2006, the portions of inequality attributed to different opportunities rise, in Argentina and Brazil respectively: in mathematics (120\% and 120\%), sciences (104\% and 144\%) and reading (286\% and 146\%). Results of similar magnitudes are observed in 2009.

Although we would be tempted to extend this recursive procedure in order to consider an even broader definition of types (e.g., combining the three dimensions simultaneously), we are limited by sample size. It is not convenient to take the three circumstances at the same time because some cells would be populated by too few individuals. Following Ferreira and Gignoux's (2008) rule of thumb, we avoid having less than 30 observations per cell. Just as an exercise, however, we have used the three circumstances together to calculate inequality of opportunity in the 'fictitious country' (i.e., 'Latin American'), using the pooled sample of all six countries. Given the larger number of

\footnotetext{
${ }^{9}$ It is still not clear to what extent these oscillations are due to changes in the composition of the samples. We shall pursue such kind of analysis in the near future.
} 
observations, such detailed definition of circumstances became possible. We have obtained similar levels of inequality of oportunity across years and subjects: 2006 (18\% in mathematics, $17 \%$ in reading, $17 \%$ in sciences) and 2009 (16\% in mathematics, $18 \%$ in reading, $17 \%$ in sciences).

It should be noticed that Chile is a country with a relative low level of gross inequality (fifth among the six countries), but it presents the highest level of inequality of opportunities when circumstances are defined in terms of parental education. The opposite happens with Argentina: it is the most unequal country in terms of gross inequality, but only the fifth (or sixth) out of six in terms of inequality of opportunities. Similar rank reversals are observed for these and other countries for both years and across subjects. We believe that provides additional support to the importance of calculating indices of inequality of opportunity. ${ }^{10}$

Before reporting some robustness checks we have undertaken, we would like to present some brief and cautious comments on differences across subjects and across years.

There are notorious differences in the importance of unfair inequality from one subject to another. The importance of each circumstance faced by a pupil could depend on the proper nature of the knowledge and skills necessary in each subject. The availability of more resources at home such as computer, internet, learning software and educational games, could help teenagers improve their performance more in mathematics than in reading. In the case of reading, possibly the absence of those physical resources is not as important as the absence of books at home or access to public libraries, or of having the opportunity of discussing and sharing ideas with others.

The time elapsed between 2006 and 2009 is a very short period, so we did not expect to observe considerable changes. Moreover, given the oscillations in the coverage of the cohort from one wave of PISA to another, we cannot be sure whether observed differences are the effect of some deliberate set of policies or whether it is simply a compositional effect. With those caveats in mind, the trend that seems to come out of the data is one of a slight decline across time in the fraction of inequality attributable to circumstances. This trend goes in the same line of many policies that have been oriented to reduce barriers in the access to education.

\footnotetext{
${ }^{10}$ We are more confident when comparing countries in terms of inequality of opportunity indices, given that such indices are obtained by means of a ratio of indices, in such a way that the unit of measure becomes irrelevant. That does not apply to gross inequality indices, which are expressed in absolute values. Since such indices are calculated over distributions which have been previously standardized, we can not be sure those rankings would be maintained had the distributions been transformed differently.
} 


\subsection{Robustness checks: bootstrap and $G E(2)$}

Estimations of inequality indices are sensitive to sample design. It is difficult to be sure whether a given calculated index is actually larger than another one when samples are small. In the face of that problem, we have checked the robustness of our results by undertaking two sensitivity analyses. First, we have used bootstrap (300 replications using random sampling with replacement 95\%). This methodology allows us to compare the series of replications and confidence intervals defined around it with the original point estimate index, and to undertake inferential statistics. Our results, shown in Tables 5 and 6 , indicate that the indices obtained from replications are extremely similar to the original ones.

Second, we have compared bootstrap calculations employing $G E(2)$ and $G E(0)$. In 2006, in eighteen rankings (three subjects times six characterizations types) of the six countries, we identify only five reversals of countries' positions when comparing $G E(0)$ and $G E(2)$ rankings. For example, in the sciences exam, with types defined as parental education and employing $G E(2)$, we have the following ranking, from fairest to unfairest: COL 6.9\%, BRA 9.1\%, ARG 10.7\%, URU 11.7\%, MEX $12.0 \%$, CHI $17.3 \%$. The ranking according to $G E(0)$, in turn, is as follows: COL $7.32 \%$, BRA 9.14\%, ARG 11.47\%, MEX 12.31\%, URU 12.42\%, CHI 17.92\%. So in 2006, rank reversal are rare and happen when two countries' differences in levels of inequality of opportunity are very close to zero. However, rank reversals are much more frequent when we compare bootstrap indices $G E(0)$ and $G E(2)$ employing 2009 data. We believe this is due to thea closer proximity of countries' calculated indices concerning 2009 as compared to those regarding 2006.

\section{$5 \quad$ Final remarks}

In this study, we assess inequality of opportunity in educational achievement in six Latin American countries. Since there is no undisputable definition of socially-inherited circumstances, we work with alternative characterizations of types (simple and composed). In some calculations we treat school type (public or private) as a socially-inherited circumstance and not as a choice. In addition to school type, we also use gender, parental education, and pair-wise combinations of those three sets of categorical variables, allowing for more complex and realistic definitions of types. That procedure also permits calculating 'incremental contributions' of each set of circumstances to inequality of opportunity as it is included in the set of conditioning factors. 
According to the year, the country, the subject and the specification of circumstances, inequality of opportunities range from less than $1 \%$ to up to $25 \%$, with considerable heterogeneity among the six countries, across subjects and across years. Robustness checks confirm most of these results.

How unequal are the opportunities for acquiring knowledge in Latin America? Are our indices of inequality of opportunity high? Are they worrying? Or are they close enough to $0 \%$ so that we can say that opportunities regarding education are close to equality in Latin America? Although we lack a basis for comparisons, which will be available in the future, we believe they are quite high and worrying. It is true that gender alone does not seem to be an important source of unfair inequalities (with a few exceptions, mostly in reading). However, when we turn to parental education and school type as conditioning factors the figures become impressive (particularly so in Argentina and Brazil for the latter). And it is worth emphasizing that they are obtained from extremely parsimonious definitions of types. ${ }^{11}$

Although it is not possible to specify the types more precisely than we have done, simply adding a second circumstance to the set of conditioning factors leads to important increases in the percentage of inequality which is attributable to unequal both in 2006 and in 2009, sometimes well above $20 \%$. This reinforces our interpretation that inequality of opportunity is substantial and a serious challenge to those countries.

Latin American countries will have to be creative in designing so-called 'EOp policies', that is, policies oriented to reducing inequities. Strategies could include either 'levelling the playing field', that is, attempting to improve the initial learning conditions of those kids belonging to worse-off types, or compensating as much as possible the unfair differences in terms of achievement, or a combination of both kinds.

\footnotetext{
${ }^{11}$ Indeed, one should always bear in mind that while a calculated close to $0 \%$ reflects a situation of equality of opportunity, it can be a simple artifact of an underspecified definition of types.
} 


\section{References}

[1] Atkinson, A. B. (1970). On the measurement of inequality, Journal of Economic Theory, 2, 244-263.

[2] Barros R. and F. Ferreira (2009). Measuring Inequality of Opportunities in Latin America and the Caribbean. World Bank.

[3] Betts, J. and Roemer, J. E. (2007). Equalizing opportunity for racial and socioeconomic groups in the United States through educational finance reform, in Schools and the Equal Opportunity Problem, P. Peterson (ed.), Cambridge, M.A.: The MIT Press.

[4] Bourguignon, F., Ferreira, F. and Menéndez, M. (2007). "Inequality of opportunity in Brazil", Review of Income and Wealth, 53, 585-618. 34

[5] Bourguignon, F., Ferreira, F. and Walton, M. (2007a). "Equity, efficiency and inequality traps: a research agenda", Journal of Economic Inequality, 5, 235-256.

[6] Checchi, D. and Peragine, V. (2010). Inequality of Opportunity in Italy. Journal of Economic Inequality, 8, 429-450.

[7] Checchi, D., Peragine, V. and Serlenga, L. (2010) Fair and Unfair Income Inequalities in Europe. IZA Discussion Paper No. 5025.

[8] Cogneau, D. and Mesplé-Somps, S. (2009). Inequality of Opportunity for Income in Five Countries of Africa, Research on Economic Inequality, 16, 99-128.

[9] Coleman, J.S., Campbell, E.Q., Hobson, C.J., Mcpartlet, J., Mood, A., Weinfeld, F.D., \& York, R.L. (1966). Equality of educational opportunity. Washington, D.C.: Government Printing Office.

[10] Dardanoni, V. G. Fields, J. Roemer and M. Sanchez Puerta (2005). How demanding should equality of opportunity be, and how much have we achieved?, in S.L. Morgan, D. Grusky and G. Fields (eds). Mobility and Inequality: Frontiers of research in Sociology and Economics, Stanford University Press, Stanford.

[11] Ferreira, F. and Gignoux, J. (2008). The measurement of inequality of opportunity: theory and an application to Latin America, World Bank Policy Research Working Paper \#4659. 
[12] Fleurbaey M. and Maniquet F. (2007). Compensation and responsibility, in The Handbook for Social Choice and Welfare, Arrow, K., Sen, A. and Suzumura, K. (eds.), Amsterdan: North Holland.

[13] Fleurbaey, M. (1995). "Equal opportunity or equal social outcome", Economics and Philosophy, $11,25-56$.

[14] Fleurbaey, M. (2008). Fairness, responsibility, and welfare. Oxford: Oxford University Press. 35

[15] Foster, J. E. and Shneyerov, A. (2000). Path independent inequality measures, Journal of Economic Theory, 91, 199-222.

[16] Hanushek, E. and Woessman, L. (2008). The role of cognitive skills in economic development, Journal of Economic Literature, 46-3, 607-668.

[17] Lefranc, A., Pistolesi, N. and Trannoy A. (2008). "Inequality of opportunities vs. inequality of outcomes: Are Western societies all alike?", Review of Income and Wealth, 54, 513-546.

[18] Lefranc, Arnaud \& Pistolesi, Nicolas \& Trannoy, Alain. (2009). "Equality of opportunity and luck: Definitions and testable conditions, with an application to income in France," Journal of Public Economics, vol. 93(11-12), 1189-1207

[19] OECD. (2009). PISA 2006: Technical report. Retrieved October 2009 from www.pisa.oecd.org.

[20] Ooghe, E., Schokkaert E. and Van de Gaer, D. (2007). "Equality of opportunity versus equality of opportunity sets", Social Choice and Welfare, 28, 209-230

[21] Peragine, V. (1999). The distribution and redistribution of opportunity. Journal of Economic Surveys 13, 37-69.

[22] Peragine, V. (2002). "Opportunity egalitarianism and income inequality", Mathematical Social Sciences, 44, 45-60.

[23] Peragine, V. (2004a). Ranking income distributions according to equality of opportunity. Journal of Economic Inequality 2, 11-30. 
[24] Peragine, V. (2004b). Measuring and implementing equality of opportunity for income. Social Choice and Welfare 22, 187-210.

[25] Peragine, V. and L. Serlenga (2007). Higher education and equality of opportunity in Italy. IZA Discussion Paper 3163.

[26] Pistolesi, N., A. Lefranc, and A. Trannoy (2005). Inequality of opportunity vs.inequality of outcomes: are Western societies all alike?. Mimeo.25

[27] Rawls, J. (1999). A theory of justice. Revised edition. Oxford Unviersity Press

[28] Rodríguez, J. G. (2008). "Partial equality-of-opportunity orderings", Social Choice and Welfare, $31,435-456$.

[29] Roemer, J.E. (1996). Theories of Distributive Justice. Harvard University Press, Cambridge, M.A.

[30] Roemer, J.E. (1998). Equality of Opportunity. Harvard University Press, Cambridge, M.A.

[31] Roemer, J.E. (2002). "Equality of opportunity: a progress report", Social Choice and Welfare, $19,455-471$.

[32] Roemer, J. E., Aaberge, R., Colombino, U., Fritzell, J., Jenkins, S., Lefranc, A., Marx, I., Page, M., Pommer, E., Ruiz-Castillo, J. (2003). "To what extent do fiscal regimes equalize opportunities for income acquisition among citizens?," Journal of Public Economics, Elsevier, vol. $87(3-4), 539-565$.

[33] Ruiz-Castillo, J. (2003). "The measurement of the inequality of opportunities", Research on Economic Inequality, 9, 1-34.

[34] Van de Gaer D., E. Schokkaert and Martinez, M. (2001). "Three meanings of intergenerational mobility", Economica, 68, 519-538.

[35] Van de Gaer, D. (1993). "Equality of opportunity and investment in human capital", Catholic University of Leuven, Faculty of Economics, no. 92.

[36] Waltenberg F. \& V. Vandenberghe (2007). What Does It Take to Achieve Equality of Opportunity in Education? An Empirical Investigation Based on Brazilian Data. Economics of Education Review, 26(6), 709-723 
[37] Willms, J.D. (2006). Learning Divides: Ten Policy Questions about the Performance and Equity of Schools and School Systems. Montreal, UNESCO Institute for Statistics.

[38] Woessmann, L. (2003). Schooling resources, educational institutions, and student performance: The international evidence. Oxford Bulletin of Economics and Statistics, 65(2), 117-170. 
Table 1: Social indicators, Latin America (six countries)

\begin{tabular}{|c|c|c|c|c|c|c|}
\hline & ARG & BRA & COL & CHI & MEX & URU \\
\hline GDP per capita $(\text { costant US } \$ \text { year } 2000)^{c}$ & 9353.5 & 4273.6 & 2955.4 & 6105.1 & 7072.1 & 7517.0 \\
\hline GDP Growth (average 2000-2006) & 2.49 & 3.17 & 4.20 & 4.30 & 2.93 & 1.11 \\
\hline Population, total (Millions) & 39.13 & 188.16 & 43.44 & 16.43 & 104.22 & 3.31 \\
\hline Poor Population ( $\%$ of total population) & $21.60^{a}$ & 33.30 & $46.8^{b}$ & 13.70 & 31.70 & $17.7^{c}$ \\
\hline GINI index & 51.90 & 60.40 & 58.49 & 52.20 & 50.60 & 46.24 \\
\hline Public spending on education, total (\% of GDP) & 4.51 & 5.05 & 4.67 & 3.19 & 5.46 & 2.92 \\
\hline Public spending on education, total (\% of government expenditure) & 13.97 & 16.18 & 14.18 & 16.02 & $25.61 \mathrm{~d}$ & 11.58 \\
\hline government expenditure (\%GDP) & 32.31 & 31.22 & 32.90 & 19.94 & $21.3^{d}$ & 25.22 \\
\hline Urban population (\% of total population) & 91.60 & 84.66 & 73.90 & 87.88 & 76.60 & 92.10 \\
\hline Illiteracy in the population aged 15 years and over ${ }^{e}$ & 2.80 & 10.38 & 7.70 & 3.50 & 8.27 & 2.21 \\
\hline Illiteracy in women age 15 years and over ( $\%$ of women $)^{e}$ & 2.70 & 10.14 & 7.78 & 3.40 & 10.17 & 1.92 \\
\hline Illiteracy in men age 15 years and over $(\% \text { of men })^{e}$ & 2.80 & 10.65 & 7.61 & 3.60 & 6.10 & 2.56 \\
\hline Net enrollment rate, primary & $98.5^{f}$ & $94.4^{f}$ & 88.50 & $94.4^{c}$ & 97.70 & 99.70 \\
\hline
\end{tabular}

Source: Word Development Indicators (WDI), (ECLAC) and Latin American and the Caribean Statistical Yearbook.

${ }^{a}$ Thirty-one urban agglomerations. ${ }^{b}$ Year 2005, ECLAC. ${ }^{c}$ Year 2007, ECLAC. ${ }^{d}$ Year 2004, WDI. ${ }^{e}$ Year 2005,

Yearbook for Argentina and Chile. ${ }^{f}$ Year 2005, Yaerbook 
Table 2: Average Scores by subject PISA (2006-2009)

\begin{tabular}{|c|c|c|c|c|c|c|c|c|c|c|c|c|c|c|}
\hline \multirow{4}{*}{$\begin{array}{c}\text { Sciences } \\
\text { total }\end{array}$} & \multicolumn{7}{|c|}{2006} & \multicolumn{7}{|c|}{2009} \\
\hline & ARG & BRA & CHI & COL & MEX & URU & OECD & ARG & BRA & CHI & COL & MEX & URU & OECD \\
\hline & 391 & 390 & 438 & 388 & 410 & 428 & 500 & 401 & 405 & 447 & 402 & 416 & 427 & 501 \\
\hline & (6.1) & (2.8) & (4.3) & $(3.4)$ & (2.7) & (2.7) & $(0.5)$ & (4.6) & $(2.4)$ & (2.9) & (3.6) & (1.8) & (2.6) & (0.8) \\
\hline \multirow[t]{2}{*}{5 th } & 218 & 254 & 295 & 247 & 281 & 274 & 340 & 228 & 275 & 315 & 268 & 291 & 268 & 341 \\
\hline & (9.9) & $(4.5)$ & $(4.8)$ & (6.3) & (4.4) & (6.8) & $(1.0)$ & (10.6) & $(3.5)$ & (4.3) & (6.6) & $(2.8)$ & $(5.2)$ & (1.0) \\
\hline \multirow[t]{2}{*}{ 95th } & 555 & 549 & 595 & 528 & 544 & 583 & 652 & 564 & 554 & 583 & 536 & 544 & 584 & 649 \\
\hline & $(6.6)$ & (5.3) & $(6.1)$ & (4.7) & $(3.5)$ & $(4.2)$ & $(0.8)$ & $(7.9)$ & $(4.8)$ & $(5.0)$ & $(4.1)$ & $(2.8)$ & $(4.2)$ & $(0.7)$ \\
\hline \multirow[t]{2}{*}{ Public } & 365 & 376 & 411 & 378 & 402 & 417 & 485 & 372 & 393 & 425 & 389 & 411 & 411 & 491 \\
\hline & $(1,67)$ & $(0,6)$ & $(2,9)$ & $(1,2)$ & $(0,8)$ & $(5,2)$ & $(0.2)$ & (1.6) & $(0.5)$ & (1.6) & $(0.9)$ & $(0.4)$ & $(1.2)$ & $(0.2)$ \\
\hline \multirow[t]{2}{*}{ Private } & 446 & 489 & 460 & 427 & 450 & 497 & 520 & 451 & 505 & 464 & 455 & 456 & 501 & 525 \\
\hline & $(2,1)$ & $(1,7)$ & $(2,5)$ & $(2,9)$ & $(1,8)$ & $(1,6)$ & $(0.5)$ & $(2.2)$ & (1.5) & (1.3) & (1.9) & (1.1) & (2.4) & $(0.4)$ \\
\hline \multirow[t]{2}{*}{ Boys } & 384 & 395 & 448 & 393 & 413 & 427 & 501 & 367 & 398 & 423 & 400 & 420 & 409 & 486 \\
\hline & (6.5) & $(3.2)$ & (5.4) & (4.1) & $(3.2)$ & $(4.0)$ & $(0.7)$ & (5.1) & $(2.6)$ & (3.5) & (4.3) & $(2.0)$ & $(3.2)$ & (0.6) \\
\hline \multirow[t]{2}{*}{ Girls } & 397 & 386 & 426 & 384 & 406 & 430 & 499 & 404 & 404 & 443 & 392 & 413 & 428 & 501 \\
\hline & (6.8) & (2.9) & $(4.4)$ & (4.1) & (2.6) & (2.7) & $(0.6)$ & $(4.8)$ & (2.6) & (3.5) & (3.7) & (1.9) & (2.6) & (0.6) \\
\hline Verbal & & & & & & & & & & & & & & \\
\hline \multirow[t]{2}{*}{ Overall } & 374 & 393 & 442 & 385 & 410 & 413 & 492 & 398 & 412 & 449 & 413 & 425 & 426 & 493 \\
\hline & $(7.2)$ & (3.7) & $(5.0)$ & (5.1) & (3.1) & (3.4) & $(0.6)$ & $(4.6)$ & (2.7) & (3.1) & (3.7) & $(2.0)$ & (2.6) & $(0.5)$ \\
\hline \multirow[t]{2}{*}{5 th } & 155 & 224 & 271 & 200 & 247 & 204 & 317 & 209 & 262 & 310 & 269 & 281 & 257 & 332 \\
\hline & (14.8) & (10.1) & $(7.5)$ & (9.1) & $(7.5)$ & (7.8) & (1.4) & (11.3) & (3.0) & (5.1) & (6.4) & $(3.9)$ & $(5.2)$ & (1.0) \\
\hline \multirow[t]{2}{*}{ 95th } & 560 & 562 & 609 & 550 & 559 & 604 & 642 & 568 & 572 & 584 & 554 & 557 & 584 & 637 \\
\hline & (5.9) & (6.8) & (6.6) & (5.9) & (3.0) & (5.7) & $(0.8)$ & (6.7) & (4.6) & (5.1) & (4.0) & $(2.4)$ & (4.5) & $(0.7)$ \\
\hline \multirow[t]{2}{*}{ Public } & 344 & 379 & 414 & 378 & 402 & 398 & 477 & 367 & 398 & 423 & 400 & 420 & 409 & 486 \\
\hline & $(2,1)$ & $(0,7)$ & $(3,3)$ & $(1,6)$ & $(1,0)$ & $(6,9)$ & $(0.2)$ & $(1.8$ & $(0.6)$ & (1.7) & (1.0) & $(0.4)$ & (1.3) & $(0.2)$ \\
\hline \multirow[t]{2}{*}{ Private } & 437 & 490 & 466 & 424 & 458 & 496 & 510 & 453 & 516 & 469 & 468 & 468 & 504 & 521 \\
\hline & $(2,5)$ & $(1,8)$ & $(2,8)$ & $(3,9)$ & $(1,9)$ & $(1,4)$ & $(0.5$ & $(2.3$ & (1.7) & (1.3) & (2.0) & (1.1) & $(2.5)$ & $(0.4)$ \\
\hline \multirow[t]{2}{*}{ Boys } & 345 & 376 & 434 & 375 & 393 & 389 & 473 & 379 & 397 & 439 & 408 & 413 & 404 & 474 \\
\hline & $(8.3)$ & $(4.3)$ & $(6.0)$ & $(5.6)$ & $(3.5)$ & $(4.4)$ & $(0.7)$ & $(5.1$ & $(2.9)$ & (3.9) & $(4.5)$ & $(2.1)$ & $(3.2)$ & $(0.6)$ \\
\hline \multirow[t]{2}{*}{ Girls } & 399 & 408 & 451 & 394 & 427 & 435 & 511 & 415 & 425 & 461 & 418 & 438 & 445 & 513 \\
\hline & $(7.4)$ & $(3.7)$ & $(5.4)$ & $(5.6)$ & $(3.0)$ & $(3.8)$ & $(0.7)$ & $(4.9)$ & $(2.8)$ & $(3.6)$ & $(4.0)$ & $(2.1)$ & $(2.8)$ & $(0.5)$ \\
\hline Math. & & & & & & & & & & & & & & \\
\hline \multirow{2}{*}{ Overall } & 381.3 & 369.5 & 411.4 & 370.0 & 405.7 & 426.8 & 497.7 & 388 & 386 & 421 & 381 & 419 & 427 & 496 \\
\hline & $(6.2)$ & $(2.9)$ & $(4.6)$ & $(3.8)$ & $(2.9)$ & $(2.6)$ & $(0.5$ & $(4.1$ & $(2.4)$ & $(3.1)$ & $(3.2)$ & $(1.8$ & $(2.6)$ & $(0.5)$ \\
\hline \multirow[t]{2}{*}{5 th } & 209 & 225 & 273 & 226 & 268 & 261 & 346 & 231 & 261 & 293 & 259 & 289 & 278 & 343 \\
\hline & (11.2) & (6.4) & $(5.6)$ & (8.4) & $(6.6)$ & (4.1) & $(1.1)$ & $(7.9)$ & $(3.0)$ & $(4.6)$ & $(5.8)$ & $(3.2)$ & $(3.9)$ & $(0.9)$ \\
\hline \multirow[t]{2}{*}{ 95th } & 543 & 530 & 561 & 515 & 546 & 587 & 645 & 543 & 531 & 559 & 509 & 547 & 578 & 643 \\
\hline & $(9.2)$ & (8.3) & $(7.7)$ & $(6.1)$ & $(4.2)$ & (5.6) & $(0.9)$ & $(7.0)$ & $(5.9)$ & $(5.8)$ & $(4.2)$ & $(3.3)$ & $(4.5)$ & $(0.8)$ \\
\hline Public & 356 & 354 & 386 & 360 & 398 & 414 & 476 & 363 & 373 & 398 & 369 & 414 & 411 & 483 \\
\hline & $(1,8)$ & $(0,9)$ & $(1,9)$ & $(1,35)$ & $(0,5)$ & $(1,6)$ & $(0.2)$ & (1.4) & $(0.5)$ & $(1.5)$ & $(0.8)$ & $(0.4)$ & (1.1) & $(0.2)$ \\
\hline Private & 436 & 474 & 432 & 415 & 448 & 495 & 518 & 433 & 485 & 438 & 430 & 457 & 500 & 518 \\
\hline & $(2,4)$ & $(2,3)$ & $(1,6)$ & $(3,5)$ & $(1,2)$ & $(2,7)$ & $(0.5)$ & $(2.1)$ & (1.6) & (1.4) & (1.9) & (1.1) & $(2.4)$ & $(0.4)$ \\
\hline Boys & 388.1 & 379.6 & 424.2 & 381.9 & 410.3 & 433.4 & 503.2 & 394 & 394 & 431 & 398 & 425 & 433 & 501 \\
\hline & $(6.5)$ & $(3.4)$ & (5.5) & $(4.1)$ & $(3.4)$ & $(3.6)$ & $(0.7)$ & $(4.5)$ & (2.4) & (3.7) & (4.0) & $(2.1)$ & $(3.0)$ & (0.6) \\
\hline Girls & 375.2 & 360.9 & 396.3 & 359.8 & 401.3 & 420.5 & 492 & 383 & 379 & 410 & 366 & 412 & 421 & 490 \\
\hline & $(7.2)$ & $(3.0)$ & $(4.7)$ & $(5.0)$ & $(3.1)$ & (3.1) & $(0.6)$ & $(4.4)$ & (2.6) & (3.6) & (3.3) & (1.9) & (2.9) & (0.6) \\
\hline
\end{tabular}

Source:Own calculations based on OECD -PISA 2006 and 2009. Stadard error in parenthesis 
Table 3: Gross inequality and Inequality of Opportunities (\%) in PISA 2006

\begin{tabular}{|c|c|c|c|c|c|c|c|}
\hline \multirow[b]{2}{*}{ MATHEMATICS } & \multirow[t]{2}{*}{$\mathrm{I}(\mathrm{X})$} & \multicolumn{6}{|c|}{$\mathrm{IO}(\mathrm{X})(\%)$} \\
\hline & & $\mathrm{I}$ & II & III & $\mathrm{A}$ & $\mathrm{B}$ & $\mathrm{C}$ \\
\hline $\mathrm{ARG}$ & 0,0368 & 9,41 & 0,60 & 16,58 & 9,99 & 20,74 & 17,48 \\
\hline BRA & 0,0306 & 11,21 & 0,90 & 19,02 & 12,32 & 24,70 & 19,90 \\
\hline $\mathrm{CHI}$ & 0,0225 & 19,70 & 3,00 & 7,89 & 22,02 & 23,79 & 10,97 \\
\hline COL & 0,0289 & 8,17 & 1,65 & 5,73 & 9,90 & 13,20 & 7,23 \\
\hline MEX & 0,0207 & 13,18 & 0,46 & 4,68 & 13,58 & 14,94 & 5,28 \\
\hline URU & 0,0276 & 13,58 & 0,60 & 9,81 & 14,25 & 18,00 & 10,50 \\
\hline LAT & 0,0289 & 9,92 & 0,92 & 11,79 & 10,68 & 17,53 & 12,62 \\
\hline SCIENCES & & I & II & III & $\mathrm{A}$ & B & $\mathrm{C}$ \\
\hline $\mathrm{ARG}$ & 0,0342 & 10,69 & 0,43 & 17,45 & 11,18 & 21,80 & 17,48 \\
\hline BRA & 0,0259 & 9,07 & 0,16 & 17,97 & 9,18 & 22,15 & 18,32 \\
\hline $\mathrm{CHI}$ & 0,0215 & 17,34 & 1,68 & 8,03 & 18,58 & 21,44 & 9,90 \\
\hline COL & 0,0244 & 6,89 & 0,38 & 5,20 & 7,45 & 11,50 & 5,86 \\
\hline MEX & 0,0186 & 12,04 & 0,32 & 4,64 & 12,25 & 14,13 & 5,20 \\
\hline URU & 0,0244 & 11,75 & 0,33 & 10,15 & 12,24 & 16,54 & 10,55 \\
\hline LAT & 0,0249 & 8,86 & 0,17 & 11,36 & 9,07 & 16,51 & 11,53 \\
\hline READING & & I & II & III & $\mathrm{A}$ & B & $\mathrm{C}$ \\
\hline $\mathrm{ARG}$ & 0,0669 & 5,53 & 7,82 & 17,01 & 15,70 & 21,35 & 23,44 \\
\hline BRA & 0,0338 & 7,67 & 3,81 & 14,58 & 12,51 & 18,88 & 18,10 \\
\hline CHI & 0,0281 & 14,24 & 1,18 & 6,77 & 15,80 & 18,21 & 8,33 \\
\hline COL & 0,0422 & 5,97 & 2,01 & 2,91 & 8,08 & 12,12 & 5,18 \\
\hline MEX & 0,0281 & 12,08 & 3,59 & 5,05 & 15,91 & 14,56 & 8,39 \\
\hline URU & 0,0487 & 10,58 & 5,39 & 10,99 & 17,07 & 16,86 & 16,10 \\
\hline LAT & 0,0368 & 7,31 & 3,46 & 9,34 & 11,16 & 13,59 & 12,61 \\
\hline
\end{tabular}

I: Parental Education II: Gender III: Type of school A=I+ II. Parental Education + Gender; B= I+ III. Parental Education + Type of School; C=II+III Gender + Type of School 
Table 4: Gross inequality and Inequality of Opportunities (\%) in PISA 2009

\begin{tabular}{|c|c|c|c|c|c|c|c|}
\hline \multirow[b]{2}{*}{ MATHEMATICS } & \multirow[t]{2}{*}{$\mathrm{I}(\mathrm{X})$} & \multicolumn{6}{|c|}{$\mathrm{IO}(\mathrm{X})(\%)$} \\
\hline & & I & II & III & $\mathrm{A}$ & $\mathrm{B}$ & $\mathrm{C}$ \\
\hline ARG & 0,0288 & 11,22 & 0,42 & 13,24 & 11,90 & 20,62 & 14,11 \\
\hline BRA & 0,0213 & 7,83 & 1,10 & 19,59 & 8,70 & 22,94 & 20,94 \\
\hline CHI & 0,0178 & 13,49 & 1,47 & 6,58 & 15,22 & 16,56 & 8,34 \\
\hline COL & 0,0199 & 11,10 & 5,19 & 11,00 & 15,88 & 17,35 & 15,88 \\
\hline MEX & 0,0173 & 10,25 & 0,88 & 3,52 & 10,92 & 11,72 & 4,37 \\
\hline URU & 0,0227 & 17,03 & 0,64 & 13,90 & 17,64 & 22,36 & 14,45 \\
\hline LAT & 0,0222 & 8,24 & 1,30 & 10,16 & 9,20 & 15,21 & 11,51 \\
\hline SCIEI & & I & II & III & A & B & $\mathrm{C}$ \\
\hline ARG & 0,0325 & 11,17 & 0,64 & 16,37 & 12,09 & 23,27 & 16,93 \\
\hline BRA & 0,0206 & 8,06 & 0,07 & 18,45 & 8,27 & 22,23 & 18,60 \\
\hline CHI & 0,0165 & 10,36 & 0,23 & 6,34 & 10,80 & 13,68 & 6,76 \\
\hline COL & 0,0206 & 8,98 & 1,96 & 11,46 & 10,75 & 16,22 & 13,09 \\
\hline MEX & 0,0169 & 11,42 & 0,28 & 4,03 & 11,63 & 12,97 & 4,40 \\
\hline URU & 0,0256 & 17,45 & 0,23 & 13,78 & 18,07 & 22,45 & 13,98 \\
\hline LAT & 0,0218 & 9,00 & 0,16 & 11,51 & 9,16 & 16,77 & 11,70 \\
\hline READ & & I & II & III & A & B & C \\
\hline ARG & 0,0381 & 10,07 & 4,90 & 17,02 & 15,16 & 22,68 & 19,85 \\
\hline BRA & 0,0257 & 7,01 & 3,20 & 16,42 & 11,04 & 20,04 & 19,32 \\
\hline CHI & 0,0168 & 11,78 & 3,05 & 8,28 & 14,84 & 16,15 & 10,77 \\
\hline COL & 0,0219 & 8,16 & 0,35 & 10,12 & 9,21 & 14,81 & 10,83 \\
\hline MEX & 0,0195 & 10,72 & 2,80 & 4,05 & 14,12 & 12,55 & 6,73 \\
\hline URU & 0,0275 & 16,55 & 5,80 & 14,47 & 23,83 & 22,51 & 20,28 \\
\hline LAT & 0,0259 & 7,96 & 2,60 & 10,41 & 11,30 & 15,25 & 12,84 \\
\hline
\end{tabular}

I: Parental Education II: Gender III: Type of school A=I+ II. Parental Education + Gender; B= I+ III. Parental Education + Type of School; C=II+III Gender + Type of School 
Table 5: Incremental Contribution of each Circumstance

\begin{tabular}{|c|c|c|c|c|c|c|}
\hline \multirow[b]{2}{*}{ MATHEMATICS } & \multicolumn{3}{|c|}{2006} & \multicolumn{3}{|c|}{2009} \\
\hline & $\mathbf{A} / \mathbf{I}$ & $\mathbf{B} / \mathbf{I}$ & C/III & $\mathbf{A} / \mathbf{I}$ & $\mathbf{B} / \mathbf{I}$ & $\mathrm{C} / \mathrm{II}$ \\
\hline ARG & 1.06 & 2.20 & 1.05 & 1.06 & 1.84 & 1.07 \\
\hline BRA & 1.10 & 2.20 & 1.05 & 1.11 & 2.93 & 1.07 \\
\hline CHI & 1.12 & 1.21 & 1.39 & 1.13 & 1.23 & 1.27 \\
\hline COL & 1.21 & 1.61 & 1.26 & 1.43 & 1.56 & 1.44 \\
\hline MEX & 1.03 & 1.13 & 1.13 & 1.07 & 1.14 & 1.24 \\
\hline URU & 1.05 & 1.33 & 1.07 & 1.04 & 1.31 & 1.04 \\
\hline LAT AM. & 1.08 & 1.77 & 1.07 & 1.12 & 1.85 & 1.13 \\
\hline \multicolumn{7}{|l|}{ SCIENCES } \\
\hline ARG & 1.05 & 2.04 & 1.00 & 1.08 & 2.08 & 1.03 \\
\hline BRA & 1.01 & 2.44 & 1.02 & 1.03 & 2.76 & 1.01 \\
\hline CHI & 1.07 & 1.24 & 1.23 & 1.04 & 1.32 & 1.06 \\
\hline COL & 1.08 & 1.67 & 1.13 & 1.20 & 1.81 & 1.14 \\
\hline MEX & 1.02 & 1.17 & 1.12 & 1.02 & 1.14 & 1.09 \\
\hline URU & 1.04 & 1.41 & 1.04 & 1.04 & 1.29 & 1.01 \\
\hline LAT AM. & 1.02 & 1.86 & 1.01 & 1.02 & 1.86 & 1.02 \\
\hline \multicolumn{7}{|l|}{ READING } \\
\hline ARG & 2.84 & 3.86 & 1.38 & 1.50 & 2.25 & 1.17 \\
\hline BRA & 1.63 & 2.46 & 1.24 & 1.58 & 2.86 & 1.18 \\
\hline CHI & 1.11 & 1.28 & 1.23 & 1.26 & 1.37 & 1.30 \\
\hline COL & 1.35 & 2.03 & 1.78 & 1.13 & 1.82 & 1.07 \\
\hline MEX & 1.32 & 1.21 & 1.66 & 1.32 & 1.17 & 1.66 \\
\hline URU & 1.61 & 1.59 & 1.46 & 1.44 & 1.36 & 1.40 \\
\hline LAT AM. & 1.53 & 1.86 & 1.35 & 1.42 & 1.92 & 1.23 \\
\hline
\end{tabular}

I: Parental Education II: Gender III: Type of school

$\mathrm{A}=\mathrm{I}+$ II. Parental Education + Gender; B= I+ III. Parental Education +

Type of School; C=II+III Gender + Type of School 
Table 6: Average of \% $\mathrm{IO}(\mathrm{X})$ using $\mathrm{GE}(0)$.

\begin{tabular}{|c|c|c|c|c|c|c|c|c|c|c|c|c|}
\hline \multirow[b]{2}{*}{ MATHEMATICS } & \multicolumn{6}{|c|}{ PISA 2006} & \multicolumn{6}{|c|}{ PISA 2009} \\
\hline & I & II & III & A & B & $\mathrm{C}$ & I & II & III & A & B & $\mathrm{C}$ \\
\hline ARG & 9,50 & 0,65 & 16,51 & 10,0 & 20,7 & 17,64 & 11,23 & 0,42 & 13,27 & 11,86 & 20,68 & 14,15 \\
\hline BRA & 11,25 & 0,91 & 19,05 & 12,3 & 24,6 & 20,03 & 7,83 & 1,10 & 19,57 & 8,70 & 22,90 & 20,90 \\
\hline CHI & 19,74 & 3,01 & 7,96 & 22,0 & 23,8 & 10,93 & 13,52 & 1,49 & 6,60 & 15,21 & 16,59 & 8,35 \\
\hline COL & 8,17 & 1,63 & 5,75 & 9,9 & 13,1 & 7,28 & 11,15 & 5,23 & 11,02 & 15,93 & 17,39 & 15,88 \\
\hline MEX & 13,16 & 0,46 & 4,70 & 13,6 & 14,9 & 5,33 & 10,26 & 0,89 & 3,51 & 10,95 & 11,72 & 4,38 \\
\hline URU & 13,62 & 0,60 & 9,83 & 14,2 & 18,0 & 10,55 & 17,04 & 0,64 & 13,93 & 17,66 & 22,39 & 14,43 \\
\hline LAT AM. & 9,93 & 0,92 & 11,80 & 10,7 & 17,5 & 12,66 & 8,25 & 1,30 & 10,15 & 9,20 & 15,20 & 11,53 \\
\hline \multicolumn{13}{|l|}{ SCIENCES } \\
\hline ARG & 10,68 & 0,43 & 17,44 & 11,3 & 21,9 & 17,54 & 11,26 & 0,64 & 16,41 & 12,06 & 23,27 & 16,93 \\
\hline BRA & 9,07 & 0,16 & 17,99 & 9,2 & 22,1 & 18,28 & 8,05 & 0,07 & 18,42 & 8,27 & 22,20 & 18,59 \\
\hline CHI & 17,31 & 1,70 & 8,05 & 18,6 & 21,4 & 9,92 & 10,31 & 0,24 & 6,37 & 10,81 & 13,72 & 6,74 \\
\hline COL & 6,90 & 0,40 & 5,25 & 7,5 & 11,4 & 5,85 & 8,94 & 1,97 & 11,53 & 10,79 & 16,26 & 13,14 \\
\hline MEX & 12,03 & 0,32 & 4,65 & 12,3 & 14,1 & 5,17 & 11,41 & 0,28 & 4,03 & 11,61 & 13,02 & 4,38 \\
\hline URU & 11,70 & 0,33 & 10,11 & 12,3 & 16,6 & 10,57 & 17,55 & 0,24 & 13,74 & 18,05 & 22,47 & 14,02 \\
\hline LAT AM. & 8,88 & 0,17 & 11,35 & 9,1 & 16,5 & 11,53 & 8,99 & 0,17 & 11,55 & 9,16 & 16,79 & 11,72 \\
\hline \multicolumn{13}{|l|}{ READING } \\
\hline ARG & 5,55 & 7,76 & 17,01 & 15,7 & 21,4 & 23,40 & 10,12 & 4,89 & 17,02 & 15,17 & 22,70 & 19,86 \\
\hline BRA & 7,73 & 3,79 & 14,59 & 12,5 & 18,9 & 18,10 & 7,01 & 3,17 & 16,40 & 11,07 & 20,03 & 19,31 \\
\hline CHI & 14,30 & 1,20 & 6,80 & 15,9 & 18,3 & 8,24 & 11,81 & 3,08 & 8,27 & 14,89 & 16,16 & 10,78 \\
\hline COL & 6,04 & 2,03 & 3,01 & 8,2 & 12,1 & 5,21 & 8,14 & 0,36 & 10,22 & 9,24 & 14,84 & 10,84 \\
\hline MEX & 12,12 & 3,59 & 5,04 & 15,8 & 14,5 & 8,39 & 10,69 & 2,79 & 4,03 & 14,12 & 12,53 & 6,76 \\
\hline URU & 10,69 & 5,38 & 10,99 & 17,1 & 17,0 & 15,99 & 16,55 & 5,82 & 14,50 & 23,84 & 22,50 & 20,39 \\
\hline LAT AM. & 7,30 & 3,47 & 9,31 & 11,2 & 13,6 & 12,63 & 7,95 & 2,59 & 10,38 & 11,31 & 15,26 & 12,84 \\
\hline
\end{tabular}

Note: Results obtained after 300 replications using random sampling with replacemente 95\%. GE(0) is the Generalized Entrophy index with $a=0$.

I: Parental Education II: Gender III: Type of school

$\mathrm{A}=\mathrm{I}+$ II. Parental Education + Gender; B= I+ III. Parental Education + Type of School; C=II+III Gender + Type of School 
Table 7: Average of $\% \mathrm{IO}(\mathrm{X})$ using $\mathrm{GE}(2)$

\begin{tabular}{|c|c|c|c|c|c|c|c|c|c|c|c|c|}
\hline & \multicolumn{6}{|c|}{ PISA 2006} & \multicolumn{6}{|c|}{ PISA 2009} \\
\hline & I & II & III & $\mathrm{A}$ & B & $\mathrm{C}$ & I & II & III & A & B & $\mathrm{C}$ \\
\hline \multicolumn{13}{|c|}{ MATHEMATICS } \\
\hline ARG & 10,32 & 0,70 & 19,33 & 10,94 & 23,99 & 20,36 & 11,12 & 5,46 & 20,04 & 16,47 & 26,63 & 22,65 \\
\hline BRA & 11,35 & 0,94 & 22,70 & 12,32 & 28,19 & 23,71 & 7,18 & 3,30 & 19,47 & 11,51 & 23,35 & 22,42 \\
\hline CHI & 20,46 & 3,10 & 8,15 & 22,74 & 25,12 & 11,18 & 12,13 & 3,23 & 8,55 & 15,45 & 16,79 & 11,06 \\
\hline COL & 8,71 & 1,74 & 6,45 & 10,48 & 14,56 & 8,09 & 8,49 & 0,36 & 11,48 & 9,73 & 16,49 & 12,13 \\
\hline MEX & 13,54 & 0,48 & 5,22 & 14,01 & 15,74 & 5,88 & 11,18 & 2,97 & 4,63 & 14,82 & 13,38 & 7,42 \\
\hline URU & 14,47 & 0,64 & 11,85 & 15,03 & 20,10 & 12,69 & 18,08 & 6,26 & 17,29 & 26,09 & 25,79 & 23,21 \\
\hline LAT AM. & 10,22 & 0,97 & 13,44 & 10,99 & 19,54 & 14,33 & 8,26 & 2,75 & 11,89 & 11,89 & 17,24 & 14,43 \\
\hline \multicolumn{13}{|c|}{ SCIENCES } \\
\hline ARG & 11,47 & 0,47 & 20,08 & 12,25 & 24,87 & 20,35 & 11,73 & 0,46 & 14,67 & 12,44 & 22,86 & 15,65 \\
\hline BRA & 9,14 & 0,17 & 20,93 & 9,27 & 25,06 & 21,28 & 7,86 & 1,12 & 22,38 & 8,72 & 26,08 & 23,73 \\
\hline CHI & 17,92 & 1,74 & 8,22 & 19,18 & 22,50 & 10,10 & 13,82 & 1,50 & 6,69 & 15,50 & 17,01 & 8,43 \\
\hline COL & 7,32 & 0,42 & 5,86 & 7,95 & 12,74 & 6,47 & 11,57 & 5,34 & 12,04 & 16,29 & 18,91 & 16,99 \\
\hline MEX & 12,31 & 0,33 & 5,06 & 12,54 & 14,72 & 5,59 & 10,49 & 0,92 & 3,85 & 11,16 & 12,24 & 4,78 \\
\hline URU & 12,42 & 0,34 & 11,86 & 13,02 & 18,47 & 12,37 & 18,03 & 0,67 & 15,83 & 18,71 & 24,50 & 16,39 \\
\hline LAT AM. & 9,05 & 0,18 & 12,63 & 9,28 & 18,20 & 12,83 & 8,38 & 1,33 & 11,18 & 9,33 & 16,67 & 12,61 \\
\hline \multicolumn{13}{|c|}{ READING } \\
\hline ARG & 6,59 & 9,34 & 22,22 & 17,77 & 27,22 & 29,91 & 11,99 & 0,71 & 18,77 & 12,89 & 26,31 & 19,34 \\
\hline BRA & 8,17 & 4,13 & 18,12 & 13,48 & 22,77 & 21,59 & 8,17 & 0,08 & 21,25 & 8,40 & 25,27 & 21,41 \\
\hline CHI & 15,52 & 1,28 & 7,27 & 17,35 & 20,38 & 8,85 & 10,66 & 0,25 & 6,50 & 11,19 & 14,21 & 6,90 \\
\hline COL & 6,94 & 2,30 & 3,61 & 9,34 & 12,56 & 6,21 & 9,30 & 2,07 & 12,80 & 11,11 & 18,08 & 14,57 \\
\hline MEX & 12,86 & 3,90 & 5,91 & 16,73 & 15,96 & 9,55 & 11,65 & 0,29 & 4,45 & 11,87 & 13,58 & 4,84 \\
\hline URU & 11,83 & 6,23 & 15,21 & 19,59 & 21,19 & 20,51 & 18,95 & 0,25 & 16,14 & 19,60 & 25,17 & 16,37 \\
\hline LAT AM. & 7,85 & 3,85 & 11,27 & 12,15 & 16,03 & 14,84 & 9,16 & 0,18 & 12,86 & 9,34 & 18,48 & 13,03 \\
\hline
\end{tabular}

Note: Results obtained after 300 replications using random sampling with replacemente 95\%. GE(2) is the Generalized Entrophy index with $a=2$.

I: Parental Education II: Gender III: Type of school

$\mathrm{A}=\mathrm{I}+$ II. Parental Education + Gender; B= I+ III. Parental Education + Type of School; C=II+III Gender + Type of School 